\title{
Las invasiones gringas. El caso del anarquista ejemplar Marco Severi ${ }^{I}$
}

Averiguar qué tipo de representación dramática le corresponde al inmigrante italiano en la obra teatral Marco Severi de Roberto J. Payró constituye la principal incógnita a desvelar a lo largo de las siguientes páginas. A partir de un ángulo de observación centrado en el "gringo" - que se instala también como personaje teatral en una modernizada escena nacional a principios del siglo veinte- estos apuntes pretenden iluminar las correspondencias entre textualidad literaria y trama política. Sin perder de vista los discursos nacionalistas de las élites criollas, que estigmatizan al extranjero con las marcas de la enfermedad y el crimen, se indagará en el texto de Payró para especificar los rasgos con que el autor argentino perfila una imagen alternativa de estos nuevos actores sociales procedentes de las orillas europeas.

Palabras claves: anarquismo, nacionalismo criollo, gringos, Roberto J. Payró, Marco Severi

This article seeks to explore the type of dramatic representations of Italian immigrants in the play Marco Severi by Roberto J. Payró. Focusing on the figure of the "gringo" - who becomes a stock character at the beginning of the twentieth century in a modernized national theatre - this article seeks to shed light on the correlations between literary textuality and political context. Without losing sight of elite national discourses that malign the foreigner by ascribing to him criminality and sickness, I explore in Payró's text the traits the Argentinian author uses to outline an alternative image of these new social actors recently arrived from European shores.

Keywords: anarchism, creole nationalism, gringos, Roberto J. Payró, Marco Severi

Le leggi sono le condizioni colle quali uomini indipendenti e isolati

si unirono in società, stanchi di vivere in continuo stato di guerra. ${ }^{2}$

- Cesare Beccaria

REVISTA CANADIENSE DE ESTUdIOS HISPÁNICOS 42.3 (PRIMAVERA 2OI8) 
ESCRITOR Y NACIÓN

En Roberto J. Payró (I867-I928), nieto de inmigrantes y uno de los primeros escritores de la Argentina moderna, se cruzan - así lo expresa Germán García en la biografía del autor - la "sangre catalana con la criolla de ambas orillas del Plata, más de ésta que de aquélla" (I4). Su abuelo, Antonio Payró, un comerciante catalán arribado a las costas argentinas en tiempos de Juan Manuel de Rosas y casado con Mercedes Lavallol, una joven y reputada criolla, se instala definitivamente en Buenos Aires sin sospechar que una de las figuras intelectuales más insignes del país en el primer tercio del siguiente siglo heredará su apellido.

Los años de formación de Roberto J. Payró, como escritor y como periodista, transcurren en tres ciudades distintas: Lomas de Zamora, donde descubre la vocación por la literatura; Bahía Blanca, referente real de la literaria Pago Chico y lugar de arranque para su carrera periodística como director del diario opositor La Tribuna; y Buenos Aires, escenario de su consagración profesional en el periodo de entresiglos. ${ }^{3}$ Al llegar a la capital en I885, Payró consigue su primer empleo en la redacción de La Patria Argentina, donde trabaja codo a codo con José S. Álvarez, más conocido como Fray Mocho, y bajo la dirección de los hermanos Gutiérrez. A partir de I89I, y gracias a la intermediación de su amigo Julián Martel, autor de uno de los libros más leídos de la época, La bolsa, Payró es contratado por La Nación, diario con el que seguirá colaborando desde Europa - con Cartas informativas desde Barcelona y con Crónicas de guerra desde Bélgica - y hasta los últimos años de su vida en América.

La preocupación del escritor ante los asuntos nacionales - el caudillismo, el fraude electoral, la integración de la población inmigrante o las relaciones diplomáticas con los países vecinos - vertebra su escritura periodística e impulsa su actividad como militante del socialismo. En sus primeros años en la capital, Payró participa con ímpetu progresista en las tertulias que organizan los centros proletarios de Buenos Aires, dirige El Obrero, colabora con Martín Fierro (1904-1905) - la revista cultural del anarquismo dirigida por Alberto Ghiraldo - y contribuye a la divulgación del ideario socialista a través de conferencias y traducciones, entre las más citadas, Socialismo y Ciencia Positiva del sociólogo italiano Enrico Ferri. La inserción del joven escritor en el campo intelectual bonaerense a finales de siglo coincide con una época de fuertes turbulencias para la capital: la ciudad "modernizada" - así la nombra Ángel Rama - conoce la explosión demográfica, la irrupción de las fuerzas políticas del radicalismo y del socialismo, la difusión del pensamiento libertario y la formación de una nueva clase proletaria que sacude la urbe con huelgas y movilizaciones. 4 
Frente a este agitado panorama, Payró hace de su casa un centro de reunión y debate en que se encuentran con frecuencia José Ingenieros, Leopoldo Lugones y el pintor impresionista Martín Malharro. Tal confraternidad intelectual no se circunscribe al ámbito privado de las tertulias pues, desde el Centro Socialista de Estudios, tanto Payró como Lugones entran en contacto con personalidades políticas como Juan B. Justo, "cerebro y arquitecto" del Partido Socialista fundado en I896 (García 43). La incursión del autor de Marco Severi en el terreno de la política es menos controvertida que la de su camarada, pues se mantendrá fiel a sus convicciones ideológicas que, alejadas de la acción violenta y de las posturas exaltadas del socialismo revolucionario, no experimentan virajes significativos durante sus años de madurez. 5

La obra de Payró encarna también una realidad novedosa de ese periodo: la profesionalización del escritor frente a la tradición de los escritores gentleman de la generación del 8o. Su figura conquista un lugar para el escritor en la estructura social de la nación, instaurando para sí y para su gremio "un nuevo poder, independiente del político, económico o religioso, que proyecta legislar acerca de la cultura y que elabora coherentemente sus mitos" (Altamirano y Sarlo 80). El escritor, "profesional libre" - prosiguen Altamirano y Sarlo - "se independiza de los resortes políticos y puede desarrollar su misión sin condicionamientos ... Los escritores del Centenario le dan un impulso decisivo a un proceso que había comenzado con el modernismo: el de la diferenciación de los escritores respecto de la 'buena sociedad' y el de incorporación a la capa intelectual de hombres que no pertenecían a familias oligárquicas (aparecen entonces los primeros apellidos judíos e italianos de la literatura argentina)" (80, 2I4). Es el caso de los hermanos Discépolo, del sainetista Carlos Mauricio Pacheco y también el de Payró quien, con El casamiento de Laucha (1906), Pago Chico (1908) y Divertidas aventuras del nieto de Juan Moreira (1910), convierte la materia narrativa en canal de denuncia de la política criolla.

Las tres obras recomponen la imagen de un mundo que se desmorona, una nación socavada por el compadraje y las corruptelas. Por sus páginas desfilan los malandrines que pueblan la sociedad argentina: Laucha, pícaro rescatado de la tradición castellana - convertido aquí en un criollo "arratonado" - que, junto a su compinche italiano, el cura Papagna, estafan a Carolina, la gringa trabajadora; Mauricio Gómez Herrera, nieto del que fuera un legendario héroe de la pampa, reducido a político arribista; $y$, en la provincia de Pago Chico, todo un séquito de criollos y cocoliches, avariciosos y oportunistas, escudriñados por el ojo del periodista Julián Viera, alter ego del autor. ${ }^{6}$ Beatriz Sarlo sitúa a Payró entre los objetores de aquel sector de la élite criolla que "consideraba el poder como una propiedad a la que tenía 
derecho por tradición política y social, por peso económico y por ilustración" (Prólogo xxxviii). En abierta oposición frente a tal sistema de privilegios, Payró redefine en sus obras la contraposición entre las fuerzas de la civilización y de la barbarie. La clásica dicotomía sarmientina brinda un esquema para organizar la materia literaria según un encuadre ideológico: por un lado, los elementos del desorden, la aristocracia del dinero y las malas prácticas de la republica oligárquica; por otro, las ideas del progreso, de la justicia y la igualdad social.7 Por tal vocación de denuncia, su obra es leída hoy en día como un documento de época, una especie de testimonio costumbrista. Aunque en esos últimos años del siglo llega a la Argentina Rubén Darío, y Payró establece una duradera amistad con él, el argentino no se convertirá en su epígono. ${ }^{8}$ Sus convicciones se alejan de las darianas: el libro ha de ser una pantalla donde reproducir de manera verosímil la realidad y las tramas han de ajustarse a ella con el fin de enderezar sus aspectos más endebles. 9

UNA DRAMATURGIA COMPROMETIDA

El juicio de la crítica es unánime a la hora de identificar los nombres de los dos pioneros del teatro argentino moderno: Florencio Sánchez y Roberto J. Payró. Cuenta Roberto Giusti cómo este último replica la atribución de tal carácter fundacional a su teatro, ubicándose más bien entre sus "demoledores" (27). Por su parte, Graciela Montes reconstruye en el siguiente fragmento el panorama de cambios en que ha de contextualizarse la obra del autor de Marco Severi:

Hacia finales del siglo xix y sobre todo en los primeros años del xx se dan por primera vez en el país las condiciones que posibilitan el surgimiento vigoroso de un teatro nacional. Los autores criollos dan a luz sus primeras piezas: Nemesio Trejo, Ezequiel Soria y Enrique García Velloso llevan a escena personajes urbanos característicos, porteños y gringos. ... Es entonces, concretamente en I9O2, cuando Payró empieza a estrenar obras. Y no solo Payró. Es una eclosión: Soria, García Velloso, Coronado, Granada, Sánchez, Laferrère. Florencio Sánchez y Payró serán considerados luego como los pilares del llamado "teatro nacional". (92)

Canción trágica, su primera obra dramática, es estrenada por la Compañía de José Podestá en 1902, año de grandes éxitos para el Apolo y en el que arranca la conocida como "época de oro" del teatro nacional.ıo Tres años después, en 1905, aparece Marco Severi, la más popular entre las obras de Payró y, sin lugar a duda, su mayor éxito en taquilla. Giusti afirma que con ella y con El triunfo de los otros "nace el teatro de ideas en Argentina" y subrayan su naturaleza "revolucionaria" (20). La escritura teatral será 
retomada por Payró a su vuelta de Europa con la comedia Vivir quiero conmigo (1923), el sainete Mientraiga (1925), Fuego en el rastrojo (1925) y Alegría (1928), pieza protagonizada por un clown circense convertido en un pioneer patagónico. Una vez más, el espacio literario es ocupado por personajes que encarnan el ideario social de su autor, llevando a escena cuestiones candentes que atañen a la sociedad argentina de la época. Se trata, en suma, de un teatro que, además de desligarse "del gaucho matrero" y abandonar "la parodia del sainete hispano" (García II7), tiende a la elaboración de ideales colectivos y a participar activamente en el debate político de su tiempo. Así sucede en Marco Severi, cuyos resortes teatrales sirven a Payró para dramatizar una determinada situación social - la aplicación de la Ley de Residencia (1902) - y en la que el espacio escénico se convierte en escenario para la pugna dialéctica. ${ }^{11}$ La obra, al llevar a escena la vulnerabilidad del inmigrante bajo la amenaza de expulsión, hace eco de las reivindicaciones libertarias y comparte con ellas la concepción de la obra de arte como herramienta de cambio social, aunque sin comulgar con la praxis violenta del anarquismo:12

Payró no está con quienes opinan que lo primero es sembrar el desorden y la confusión. Él, como [Juan B.] Justo, entiende que es necesario esclarecer las mentes, sembrar ideas, despertar las conciencias; que la labor es de perseverancia. ... Como el diario y la tribuna partidaria, utiliza el escenario teatral para plantear sus reclamos y provocar la discusión de problemas del momento. Siguiendo la ruta ibseniana, hizo teatro de tesis, que es teatro de ideas y de debate. En tal sentido la obra más representativa, del autor y de la escuela que él introdujo en nuestro país, es Marco Severi. (García 122-23)

La obra se convierte en un éxito rotundo y equipara su prestigio al de Florencio Sánchez, que pocos meses antes había logrado con La Gringa una popularidad sin precedentes en la tradición nacional. En Evocaciones de un porteño viejo, Payró transcribe una carta que José Ingenieros le envía desde Europa, tras la noticia de su aplaudido estreno: "Ahora, querido Roberto, leo con emoción que Marco Severi triunfa con brillo inusitado entre nosotros para que nadie pueda dudar de tu talento que te he oído esparcir a borbotones en una sobremesa o entre dos chopps" (82). A pesar de la euforia inicial, la obra conoce en los años siguientes un progresivo abandono por parte de los lectores y de la crítica, debido quizás a la naturaleza crítica de un texto cuyo valor literario acaba por replegarse ante la misma legislación que combate. 
LA INMIGRACIÓN DEL BEL PAESE

Antes de dar paso al análisis de la obra Marco Severi, conviene recordar la preocupación de su autor por la cuestión inmigratoria. Roberto J. Payró, "primer periodista moderno por su movilidad ubicua" según Larra (85), hace un diagnóstico de los principales obstáculos para el desarrollo nacional: el latifundio y el desierto - este último ya vislumbrado por Sarmiento, para quien el mal de la república radicaba en su inmensidad geográfica.ı3 Uno de los biógrafos de Payró apunta esta coincidencia:

Payró, como Sarmiento, como Alberdi, ve el trágico mal del país. El desierto. Y ve más: el acaparamiento de las tierras. De ahí que abogue por una inmigración sana que inunde estas tierras olvidadas por el gobierno central. Para ellos es preciso que se le otorguen facilidades al extranjero. Alega: "Hay que dar al inmigrante algo más que palabras y ese algo lo tenemos a nuestra disposición: tierra fértil de la que hará su segunda patria si se le protege sin incomodarlo, con el mínimo posible de gobierno". (Larra 92)

Payró, en tiempos de Julio Argentino Roca, revitaliza el menoscabado lema de Alberdi "Gobernar es poblar" y defiende la acción civilizadora de la inmigración, destinada a habitar la pampa vacía con pequeños productores, capaces de disputar el monopolio de las tierras a las grandes compañías de especuladores. Para ello, es necesaria una política que promueva los derechos civiles y políticos de los extranjeros. Esa tarea de persuasión es la que ensaya Payró tras su viaje patagónico de 1898 en las páginas de $L a$ Australia argentina, en cuyo prólogo Bartolomé Mitre escribe: "Por eso su libro, como comentario de un mapa geográfico hasta hoy casi mudo, importará la toma de posesión, en nombre de la literatura, de un territorio casi ignorado, que forma parte integrante de la soberanía argentina" (vi).14

Para Sarlo, la cuestión inmigratoria preocupa a Payró "por lo menos desde I895, cuando publica en La Nación, y luego recopila en libro, Los italianos en Argentina" (xxii). En un total de ocho artículos sustentados por numerosos datos y estadísticas, el periodista - cuya ascendencia también está atravesada por la marca de la extranjería - se propone la tarea de recordar a los lectores la influencia que ha tenido, en el desarrollo argentino, la colonia italiana, "la más numerosa y activa que se haya radicado en el país" (Payró, Los italianos I). Para cumplir tal propósito, distingue dos tipos de beneficios aportados por esa inmigración: los de orden material y los de tipo intelectual. Italia, país veterano en luchas sociales, exporta con sus emigrantes ideas tolerantes y progresistas, un pensamiento crítico que es promotor de la "idea política, moral y filosófica" (Payró, Los italianos 6), así 
como de un léxico variopinto que llega a las costas platenses para aderezar el vocabulario criollo con sus voces dialectales.

En sus artículos y como prueba de los progresos materiales asociados a la inmigración latina, Payró rescata la memoria de aquellos apellidos italianos - Rossetti, Mossotti y Pellegrini, entre otros - detentados por ilustres comerciantes, hombres de industria y militares argentinos. Estos, junto a ingenieros, arquitectos, pintores, escultores, músicos, naturalistas y matemáticos, además de importar sus buenas costumbres al país de acogida, hacen propios los hábitos nacionales con asombrosa facilidad. Los hijos de italianos - especifica Payró - "muestran la más unánime tendencia a considerarse hijos del país" (Los italianos Io). Entre los demás méritos que convierten a los italianos afincados en Argentina en modélicos ciudadanos de la república, Payró refiere la acción de sus tropas durante las campañas por la conquista del desierto, en la Guerra del Paraguay o en la Batalla de Pavón. ${ }^{15}$ Además de su espíritu voluntarioso y combativo, el italiano ha llevado a cabo un papel indiscutible como repoblador, pues ha fundado asentamientos en buena parte de la pampa desértica, generando el movimiento humano necesario para el desarrollo agrícola: sus hombres trabajando el campo con diligencia y sus mujeres dando a la nación una prole más numerosa que la argentina. ${ }^{16}$ La perspectiva que despliega Payró en sus artículos, con los que busca persuadir al lector criollo de la influencia benéfica de la inmigración de ultramar, en particular la de origen italiano, deja entrever un elemento del trasfondo político que brota en esos años y se incrementa en los siguientes, esto es, las reticencias, cada vez más exacerbadas, de las élites hacia los recién llegados. Payró exhorta a sus lectores a defender y a confiar en el arraigo de estos contingentes, destinados a crear junto a los argentinos una "sólida amalgama" (59). ${ }^{17}$

PUERTAS PARA BABEL

Desde los años en que Sarmiento y Alberdi imaginaban el primer modelo de país, construir nación significaba, en Argentina, definir una política inmigratoria, en un primer momento como impulso modernizante $\mathrm{y}$, décadas después, como manera de hacer frente a la amenaza de disgregación que acarreaba la presencia masiva de extranjeros en suelo argentino. En palabras de Bertoni, a partir de la crisis del noventa, se advierte dentro del vasto movimiento patriótico, "la constitución de un polo de opinión que manifiesta una concepción esencialista, excluyente y defensiva de la nación" (3I4).18 La puesta en circulación de una concepción cultural y política de la nación basada en rasgos unívocos y tradicionales se debe a la labor programática de un conjunto de personalidades, entroncadas en la mayoría de los casos con distinguidas familias criollas del 
interior, entre las que despuntan tres nombres: Manuel Gálvez, Ricardo Rojas y Leopoldo Lugones. Todos ellos, escritores profesionales que se atribuyen el papel civil de fundadores de lo nacional, dan origen a la que Fernando Devoto ha llamado la "primera generación nacionalista" (49), caracterizada por una directriz marcadamente cultural. Ofreciéndose como alternativa ante los agentes del desorden y la heterogeneidad reinante, estos intelectuales participan en la formación de la tradición argentina a través de una labor compleja: la búsqueda de las esencias nacionales, en el plano teórico, y la elaboración de medidas concretas de argentinización, en el práctico. ${ }^{19}$

Por lo que respecta a la literatura de ideas, Óscar Terán, que centra su estudio en los discursos producidos por la élite argentina entre i88o y el Centenario, demuestra que también la cultura científica sostiene las argumentaciones nacionalistas. A partir de la lectura de la obra ensayística producida por Miguel Cané, José María Ramos Mejías, Carlos Octavio Bunge, Ernesto Quesada y José Ingenieros - agentes culturales ubicados en la cumbre de la pirámide social e intelectual porteña - Terán demuestra cómo las ideas, que habían empezado a delinearse desde la narrativa realista y naturalista finisecular, trazan, también en el ensayo de pretensiones científicas del novecientos, "un escenario social amenazado por la literal infiltración de personajes portadores del virus mercantilista" (53). Al respecto, recuerda la exhortación de Cané a los "argentinos disminuidos" ante un mundo heterogéneo, híbrido y en decadencia: "Salvemos nuestro predominio legítimo. Cerremos el círculo y velemos sobre él" (Terán 77); las advertencias de Ramos Mejías acerca de la gobernabilidad de las multitudes y su mirada darwinista sobre el inmigrante la perspectiva racial que recorre el diagnóstico sobre los males nacionales recogida por Bunge en Nuestra América; la mirada sociológica de Quesada ante los peligros que acarrea el "neocriollo" por la mala mezcla que en él se engendra: y, en último lugar, la propuesta psiquiátrica del director del Instituto de Criminología José Ingenieros, destinada a "integrar el disenso negociable y segregar a los estratos sociales incapacitados o renuentes a integrarse al proyecto de la modernidad" (Ingenieros 293). En esos años, el saber criminológico acrecienta su prestigio hasta alcanzar un elevado estatuto social, tal y como demuestra la vitalidad e internacionalización de las revistas Criminalogía moderna, dirigida por Pietro Gori entre 1898 y 1900, y Archivos de Criminología, Medicina Legal y Psiquiatría, dirigida por José Ingenieros entre I902 y 1913. Ambos directores - representantes ilustres, aunque atípicos del saber criminológico - se sitúan entre los opositores de una tendencia común dentro de la disciplina, en cuyo seno se afinca la identificación científica entre la inmigración y crimen. Para la elaboración de tal nexo, Cesare 
Lombroso, fundador de la antropología criminal, constituye una figura de referencia en Argentina, donde los postulados de la Scuola positivista italiana son difundidos a través de sus colaboraciones en el diario La Nación y gracias a la labor divulgativa de Cornelio Moyano Gacitúa, profesor de Derecho Penal en Córdoba. En su trabajo con mayor repercusión, La delincuencia argentina (1905), Gacitúa exacerba la violencia de las posturas criminológicas contra la inmigración, en particular contra la italiana y la española, por ser aquellas con mayor índice de criminalidad en Europa, y cuya propensión a delinquir aumenta en el extranjero. Al escribir en sus páginas, "La ciencia nos enseña que con el carácter emprendedor, inteligente, desprendido, inventivo y artístico de los italianos viene el residuo de su alta criminalidad de sangre" (Gacitúa io), su autor convierte el pensamiento científico en instrumento legitimador de la purga racial. Pues si bien ya existían en la sociedad argentina estereotipos negativos en relación con la figura del inmigrante, el estigma se hace indeleble, consustancial a la naturaleza del recién llegado, cuando recae sobre este el peso de la argumentación científica. La que fuera pocos años atrás la Babel del Plata es ahora una ciudad en vías de modernizarse, pero también un desordenado escenario para el vicio y el crimen, una ciudad que "no defrauda a los criminólogos", que encuentran allí una "amarga confirmación" de sus teorías (Scarzanella 55).

IL FU MARCO SEVERI

Sin perder de vista el papel crucial que desempeñan los materiales simbólicos y culturales en la conformación del debate de la nación durante los años del Centenario, se da paso, a continuación, a un caso de escritura teatral en que la representación del italiano se opone frontalmente a la dominante en el discurso de las élites. Roberto J. Payró dialoga con este contexto en pugna para ofrecer una representación alternativa del inmigrante italiano, liberando su figura del corsé difamatorio que le imponen los representantes del nacionalismo. A las operaciones de deslegitimación pública de la figura del "tano" 20 se suman los estereotipos puestos en circulación por las "ficciones somáticas" - tal y como las define Gabriela Nouzeilles - que alzan la voz en contra de la inmigración inferior europea. Títulos como ¿Inocentes o culpables? (1884), de Antonio Argerich (I884), Sin rumbo (1885) y En la sangre (1887), de Eugenio Cambaceres, Carlo Lanza (I890), de Eduardo Gutiérrez y La bolsa (I890), de Julián Martel representan el paradigma de las escrituras narrativas de fin de siglo que incorporan a sus tramas la encarnizada xenofobia de sus autores. ${ }^{21}$

En abierta contraposición con los anteriores, que ven en el extranjero un cuerpo tarado - germen del desorden y la enfermedad - Payró organiza 
su razonamiento a partir de la equivalencia entre inmigración y civilización. Casi sin excepciones, la caracterización de los italianos delineada en sus cuentos y novelas concuerda con este prisma ideológico: así, en $E l$ casamiento de Laucha, la gringa Carolina es la representante del progreso mientras que el criollo Laucha encarna al estafador; en Violines y toneles, Luiggin y Roccavecchia son los nombres de otros dos "tanos", el primero un carpintero piamontés y el segundo un noble venido a menos en América, ambos solícitos trabajadores en la patria nuova. Sin embargo, de su amplia galería de italianos, la figura más célebre es la de Marco Severi, protagonista de una pieza teatral cuya proyección política y ricas valencias simbólicas justifican la andadura de esta investigación.

La historia de Marco Severi, dramatizada por Payró en la pieza teatral homónima, tematiza la amenaza de expulsión y, por consiguiente, el riesgo de un segundo desarraigo - una suerte de doble exilio, esta vez desde la patria de acogida a la patria de origen - que concierne a un elevado número de extranjeros con un pasado "irregular" radicados en Argentina. ${ }^{22}$ Bajo el nombre de Don Luis Vernengo, dueño de un próspero negocio en Buenos Aires, se esconde Marco Severi, un prófugo romano perseguido en Italia por falsificador y anarquista. El cambio de nombre es solo el primer indicio de sus tentativas de inserción en tanto que "criollo nuevo" en suelo argentino. La nueva vida de Vernengo se corresponde con la de un personaje virtuoso, casado con una criolla y alejado de la praxis libertaria de su juventud. Sin embargo, la denuncia del chivato Benito detona el conflicto y obliga al protagonista a relatar su historia, quedando desvelada su auténtica identidad. La fatal anagnórisis arrastra al protagonista ante el Juez de Instrucción, personaje clemente, aunque constreñido a aplicar la Ley de Residencia, según la cual "se podrá, por decreto, ordenar la salida del territorio de la nación, a todo extranjero que haya sido condenado o sea perseguido por los tribunales nacionales o extranjeros, por crímenes o delitos de derecho común" (Cané 3 ). La obra de Payró disiente públicamente de la puesta en práctica de una iniciativa que, redactada por el político y escritor Miguel Cané, es concebida como arma legislativa para preservar el orden social a través de la "expulsión de los elementos de perversión que minan su organismo" (125).23 La habilitación de esta ley, que se produce bajo el gobierno conservador de Julio A. Roca, supone un fuerte respaldo legislativo al modelo excluyente de nación que se ve apoyado por los diversos sectores del higienismo y la criminología desde finales del xix. Según tal entramado ideológico, cuyo fin es revestir el cuerpo de la nación de medidas que lo protejan frente al propagarse de "agentes mórbidos" (Gacitúa I3), personajes como Vernengo-Severi son identificados como el 
elemento patógeno sobre el que resulta necesario practicar la profilaxis social. ${ }^{24}$

Con Marco Severi, Payró presenta ante el público argentino una obra de tesis que cuestiona la legitimidad de tales prácticas discursivas y que aboga por la derogación de dicha ley: la escenificación del conflicto, protagonizado por un inmigrante ejemplar de origen italiano, no es más que la traducción en clave dramática de una convicción ideológica. Los personajes, sus acciones y el contexto funcionan como los exempla particulares de una argumentación en defensa del inmigrante, cuyos derechos de residencia son vulnerados por un decreto legislativo de dudosa ecuanimidad. La centralidad detentada por el inmigrante italiano y la perspectiva ideológica son las razones que han motivado el estudio de esta pieza, cuyo objetivo es rescatar una entre las más genuinas imágenes alternativas del "gringo", forjadas en la primera década de la centuria. Por consiguiente, de los cuatro elementos fundamentales que componen toda obra teatral - espacio, tiempo, personaje y público - según la clasificación de José Luis García Barrientos (47), en este análisis se dará prioridad al tercero de ellos.

El eje espacio-temporal que acompaña el desenvolverse de los hechos de Marco Severi se corresponde con el del Buenos Aires de principios de siglo. Payró construye un marco realista, situando frente a un entorno familiar al espectador de la época, capaz de reconocer el paisaje que se perfila sobre las tablas. El principio de verosimilitud se mantiene con el fin de instar a su público a una toma de postura ante el conflicto que allí queda delineado; prueba de su éxito son las trifulcas que se producen tras las representaciones, en que el actor de Benito - el espía responsable del aprieto de Vernengo - es increpado e incluso agredido por los asistentes a la función, tal y como documentan varias críticas teatrales de la época recogidas por Germán García (77). A lo largo de los tres actos, son dos las escenografías que sirven para el trasfondo teatral: "un vasto y antiguo almacén", en los dos primeros, y "un saloncito de comisaría", en el tercero. Las acotaciones son escuetas pues la escena aparece despojada de cualquier elemento accesorio: el espacio dramático es imaginado como un plano desierto donde los pocos objetos que asoman están al servicio de las ideas. Así, la primera decoración presenta, en uno de los extremos del escenario, el taller tipográfico, con sus "máquinas y útiles de imprenta" en funcionamiento, y, en el otro, el comedor de la casa de la familia Vernengo. La convivencia de ambos espacios, el laboral y el doméstico, complementa la caracterización de Severi, un personaje consagrado totalmente a la bienandanza de su negocio. Asimismo, el carácter inminente de la expulsión, la rapidez con que se suceden los acontecimientos - en menos de una jornada - imprime a la obra un ritmo de apresuramiento que concuerda con 
la idea de devastación instantánea provocada por la Ley de Residencia. Basta una orden judicial levantada por un delito prescrito para provocar el desmoronamiento de un núcleo familiar y convertir en ruina un negocio próspero.

El drama de Payró, estrenado en el Teatro Rivadavia por la Compañía Podestá, construye una imagen irrefutable de un mundo, en que los términos de civilización y barbarie ocupan un lugar unívoco. El personaje de Vernengo representa a la víctima inocente, el cuerpo dramático encargado de conducir la tesis ideológica del autor y de conmover a su auditorio. Tal y como se infiere del título de la pieza, el intreccio teatral se concentra únicamente en su persona, cuya presencia en escena es constante: si no aparece en ella físicamente, el resto de los personajes se encargan de mantenerlo presente refiriendo su modélica conducta. No quedan márgenes para ninguna acción secundaria, no existen zonas alternativas más allá de su conflicto personal y la amenaza de extradición viene a saturar el perímetro de toda la obra; la urdimbre entre Vernengo y su entorno es tan estrecha, su arraigo tan profundo, que los efectos de su posible expatriación afectarían al resto del elenco, dejando huérfano al hijo, viuda a la esposa y sin empleo a sus trabajadores:

Antonio. - ¡Y es que Don Luis es tan bueno!

Juan. - ¡Más bueno que el pan! Ese sí que no se vuelve pura boca como otros patrones, que pasan por liberales y después... Ni fósforos! Ojalá que todos los que vienen de Europa fuesen como él.

...

Benito. - Ya le dije señor Juez que era un alma de Dios, bueno como el pan y hasta medio tilingo. No se mete en nada. Siempre está con la mujer y el chiquilín, como un bobeta. Pero dice que quiere que todos en la imprenta sean felices y se hagan ricos junto con él. (Payró, Marco Severi 8, 76)

La ilustre trayectoria del protagonista se quiebra ante la confesión: "Yo no me llamo Luis, yo no me llamo Vernengo. Me llamo Marco Severi" (Marco Severi 48); el personaje venerado por el elenco dramático esconde un pasado anarquista que justifica, a ojos de la ley, su expulsión de la nación en tanto que sujeto peligroso. A raíz de esa doble experiencia vital, el personaje de Vernengo se torna más complejo y la trama cobra espesor: "Soñaba que era otro hombre, que Marco Severi había muerto ... Estaba tan seguro de ser bueno, de ser honrado..." (49). La pareja Severi-Vernengo imaginada por Payró ha de leerse, entonces, como el cuerpo ideológico que conduce la tesis en despliegue al término de la pieza, donde el Juez exclama: “Hay que enmendar esa ley!" (98). En el mismo ideologema entran en colisión dos 
estereotipos de inmediato reconocimiento para el público de la época: por un lado, el del extranjero-anarquista-delincuente, cuya figura ha sido esbozada en detalle por las élites letradas más recientes; por otro, el del inmigrante-industrioso, cuya caracterización original se remonta a décadas anteriores.

En la pieza de Payró, la representación criminalizante se desplaza a favor de la ejemplarizante, dado que la vida de Vernengo en Buenos Aires es prueba de su bien hacer: el que fuera un anarquista alborotador en Italia ha encontrado en Argentina una oportunidad para medrar honradamente, cumpliendo con todos los requerimientos de nacionalización esperados del inmigrante en su segunda patria. Marco Severi se convierte en Don Luis Vernengo al contraer matrimonio con una criolla, adoptar su lengua, asimilar sus hábitos culturales e invertir en un negocio que, además, prospera en beneficio de la comunidad que lo ha acogido. La natural integración del protagonista emparienta su figura con la de aquellas personalidades ilustres que Payró había reunido algunos años atrás en Los italianos en Argentina, en cuyas páginas los inmigrantes eran realzados como hombres "vigorosos, inteligentes, de salud completa, emprendedores y constantes en el trabajo" (Io). Vernengo integra esa estirpe de hombres fuertes que participan en la construcción de la nación dado que, con su labor como agente de progreso, construye las bases para el futuro engrandecimiento de la República: "En este país bendito en el que he de vivir toda mi vida, donde están mis afectos, he tenido la suerte de que el trabajo me resultara generosamente fecundo" (Payró, Marco Severi 25).

A través de la pareja Severi-Vernengo se construye uno de los ideologemas teatrales de mayor complejidad y proyección de la época, puesto que en él se aglutinan dos representaciones del "tano" asociadas a estereotipos irreconciliables, según el prisma oficial de la época. El pasado criminal de un ciudadano modélico abre la posibilidad para la convergencia en un mismo cuerpo de las posturas enfrentadas en un debate central en la Argentina del Centenario, cuya resolución textual - en este caso, a favor del inmigrante - cuestiona el paradigma político dominante. Ante un contexto dominado por las voces de un nacionalismo atareado en la búsqueda de los valores primigenios de la argentinidad, Marco Severi representa un personaje disruptivo, cuya función principal es la de cuestionar el sistema de discriminación impuesto por las clases dirigentes. Frente a la heterogeneidad del cuerpo de la nación, Payró opta por una solución integradora, en respuesta a la exacerbación de prácticas excluyentes cada vez más virulentas. Como señalan Alicia Aisemberg y María de los Ángeles Sanz, Payró, ante la violenta fracturación del orden social, "se propone unir un universo dividido, disolver la antinomia inmigrantes-criollos" (66).25 El 
personaje de Vernengo busca reparar el lacerado nexo entre anarquismo y civilización, a la par que afianza la idea de integración entre criollos viejos y recién llegados. Se trata, en suma, de una escritura teatral que recompone sobre las tablas un mapa de piezas fracturadas, a través de un cuerpo bifronte en el que conviven armoniosamente dos realidades que las élites criollas han fijado en términos de antagonismo. Marco Severi permite, por tanto, rastrear una de las principales controversias de la época, aquélla que observa con preocupación el anclaje de los recién llegados en el presente nacional. Si Eugenio Cambaceres, desde la narrativa, Moyano Gacitúa, desde la criminología, y Ramos Mejías, desde el ensayo, colaboran entre sí para identificar en el inmigrante el perfil del homo criminalis, también Payró, aunque éste en dirección opuesta a los anteriores, participa en ese proceso de delineamiento y diagnóstico. Sus personajes, liberados de los moldes genéricos criminalizantes y patologizantes, se fraguan en respuesta a la cadena de estereotipos y cuadros clínicos oficiales que justifican los mecanismos de exclusión defendidos por las élites; a diferencia de las novelas naturalistas en que se desaconsejaba la alianza entre criollos y extranjeros, en esta pieza teatral se recupera el modelo de nación como crisol de razas imaginado por Alberdi y Sarmiento. El espectador de la época se topa por primera vez ante la perspectiva teatral del escritor profesional que, desligado de la aristocracia letrada y en diálogo con la cultura de una incipiente izquierda argentina, participa con sus obras en la construcción del imaginario nacional. Un texto como el de Marco Severi disiente públicamente de aquellos producidos por los representantes del primer nacionalismo argentino pues, mientras Ricardo Rojas, Manuel Gálvez y Leopoldo Lugones dibujan al extranjero como el causante de la degeneración colectiva, Payró se sirve del "gringo" para cuestionar la dicotomía que enfrenta los términos de civilización y barbarie. ${ }^{26}$

Otro de los aspectos que se desprende de la escritura dramática de Payró tiene que ver con los procedimientos con los que se despliega la perspectiva en defensa del inmigrante italiano. La construcción de la figura del "gringo" se sustenta aquí sobre moldes ideológicos en colisión, reconciliando perspectivas planteadas como antagónicas por el paisaje político de la década. Si en los años del Centenario, la oligarquía criolla identifica en el anarquismo y en la inmigración los óbices principales para el proyecto de modernización nacional, la pieza rescatada en estas páginas disiente también en este aspecto del discurso de la clase dirigente. En Marco Severi, los ideales libertarios del protagonista no deslucen su vida ejemplar como argentino nuevo y su semblanza se separa de aquellas monstruosas descritas en los apuntes criminológicos de Francisco de Veyga y Cornelio Gacitúa Moyano. ${ }^{27}$ La insólita convivencia en el personaje de Marco Severi 
de ejemplaridad moral y credo libertario conlleva la resemantización del consabido estereotipo: éste, al matizarse, debilita la tradicional correspondencia extranjero $=$ anarquista $=$ dinamitero y cobra una nueva valencia simbólica. Puede afirmarse entonces que a través del ideologema de Marco Severi se problematiza la supuesta naturaleza tarada del extranjero a la par que se dejan entrever las ventajas que supone, para el progreso de la nación, su correcta integración en la nueva patria.

Como último apunte, recordaré que el asalto de las tablas protagonizado por el "gringo", así como su progresivo desplazamiento hacia el centro de la acción dramática, están ligados a los cambios sociales y demográficos que se están produciendo en el país. La presencia masiva de extranjeros en escena - los mismos que desembarcan en tropel en las orillas platenses - además de funcionar como crónica teatral de las transformaciones que afectan a la vida de la urbe, prefiguran el advenimiento de un nuevo panorama político. La ubicuidad del "gringo", convertido en uno de los personajes predilectos del público porteño, es constatada por su presencia en modalidades teatrales de distinto prestigio, desde las formas populares de Carlos Mauricio Pacheco, hasta las variantes cultas de Payró o los dramas de filiación ácrata de Armando Discépolo. Ante las prácticas discursivas y las iniciativas de ley que facilitan su deportación del territorio nacional, el "gringo" arraiga con mayor fuerza en los escenarios argentinos donde toma la palabra para presentar, por primera vez, su experiencia como inmigrante: Marco Severi expone ante el auditorio sus tribulaciones, da pruebas de su labor civil en su segunda patria y demuestra su voluntad de integración frente a un panorama político que tiende a su confinamiento. La escritura de Payró brinda al inmigrante una ocasión, sin precedentes en el campo literario local, para construir una imagen de sí mismo capaz de argüir en contra de aquella que las élites letradas le han asignado. Mientras Marco Severi sube a las tablas de los escenarios porteños función tras función, la permanencia de sus compatriotas y camaradas en la ciudad de Buenos Aires se ve cohibida por el constante riesgo de encarcelamiento o deportación. El protagonismo teatral de estos inmigrantes apunta, sin embargo, a un inminente cambio en su estatuto social que determinará, a partir del triunfo de Hipólito Yrigoyen en I9I6, su incorporación definitiva en la vida política del país.

Palacký University, Olomouc 
NOTAS

I El presente artículo ha sido publicado gracias al apoyo del Ministerio de Educación, Juventud y Deporte de la República Checa.

Proyecto IGA_FF_2OI8_OI5 (Literaturas y lenguas románicas: tradiciones, tendencias contemporáneas y nuevas perspectivas).

2 Las leyes son las condiciones con las que los hombres independientes y aislados se unieron en sociedad, cansados de vivir en un estado de guerra permanente. (La traducción es mía.)

3 En ese periódico - fundado con la herencia paterna y cerrado por bancarrota en I89o - Payró combate al presidente Juárez Celman y denuncia las nefastas consecuencias que tiene para la república esa "oligarquía microscópica que se perpetúa de escándalo en escándalo” (citado en García 40).

4 La afluencia de extranjeros en el territorio argentino conoce un aumento constante en los años de entre siglos como consecuencia de las políticas de atracción de inmigrantes promovidas por Alberdi y Sarmiento. Hebe Clementi recoge los siguientes datos: mientras en el primer censo de población realizado en I869, esta asciende a I.877.490 personas, en I895 es ya de 3.959.9II, de las cuales I.004. 527 son extranjeras, y en su mayoría de procedencia italiana. El índice más alto de llegadas se concentra entre 1904 y I913, nueve años que dejan un saldo de I.538.240 inmigrantes. El aumento demográfico es corroborado por el censo de i9I4, que cuenta un total de 7.855.237 personas, de las cuales un tercio siguen siendo extranjeras (Clementi 85).

5 Raúl Larra, a propósito de su actividad política, nos refiere: "Si luego se desligó de la militancia política activa, llamado por el periodismo, por su vocación literaria, nunca, durante toda su vida, contradijo sus ideales de juventud, como lo hizo Lugones, como hicieron otros tantos. (...) Cuando en 1922 Lugones proclama 'la hora de la espada', Payró lo llamó a la realidad como un hermano mayor" (citado en Larra 84).

6 El término de "cocoliche", que en un primer momento se utiliza para nombrar al personaje italiano - normalmente parodiado- del teatro popular rioplatense, adquiere una nueva acepción a finales de siglo y se utiliza para referirse al español mezclado con el dialecto con el que se comunican entre sí los inmigrantes de origen italiano instalados en los suburbios porteños.

7 Graciela Montes señala que mientras los primeros se concentran en la narrativa, los segundos lo hacen en las obras dramáticas y las crónicas periodísticas (88).

8 Es una amistad que el mismo Rubén Darío plasma en sus "Versos de año nuevo": "iQué cambio, Dios de Dios! Payró / era mi guía, era mi heraldo" (citado en García IOI). 
9 Esta concepción de lo literario como herramienta de lo social, así como el cultivo de un estilo puesto al servicio, no del regodeo estético, sino de la regeneración del mundo civil, explica la admiración de los jóvenes autores de Boedo por el veterano Payró. Una vez instalado en Buenos Aires tras su regreso europeo, recuerda Larra que "Don Roberto oficia de mentor y consejero paternal para muchos de ellos ganándose el caro título de maestro" (227), pues "Yunque, Castelnuovo, Mariani, los Talón, Delgado Fito, Juan Guijarro, Emilio Soto, Gustavo Riccio y otros muchachos solían frecuentar su quinta de Lomas de Zamora, pasando en su compañía largas tertulias” (228).

Io Paralelamente, desde el Teatro de la Comedia, Jerónimo Podestá lleva a las tablas tres obras que marcan un salto cualitativo en la dramaturgia nacional, obteniendo la consagración para sus autores: M'hijo el dotor (1903) de Florencio Sánchez, Jettatore (1904) de Gregorio Laferrère y Sobre las ruinas (I904) de Roberto J. Payró.

II La Ley de Residencia constituye el primer intento legislativo para dotar a la República Argentina de un sistema preventivo en defensa de "los nuevos enemigos del orden social" (Cané 5). La Ley de Residencia decreta la posibilidad de expulsar a todo extranjero "que haya sido condenado o sea perseguido por los tribunales nacionales o extranjeros" (Art. Iํㅜ) o cuya conducta "pueda comprometer la seguridad nacional, turbar el orden público o la tranquilidad social” (Art. 2º̣) (Cané 3). La ley, según Miguel Cané, ha de servir "para evitar que sea con dineros ganados en suelo argentino que se adquieran las bombas destinadas a matar ancianos, mujeres y niños indefensos, como en el Liceo Barcelona, o los puñales que han de partir corazones tan nobles como el de la emperatriz Isabel o el presidente Carnot" (124). En ella, se impugna la concepción de América como tierra de promisión, destinada a abrir sus puertas a "todo vagabundo o delincuente que no encuentra ya cabida en Europa" (Cané II). El nuevo orden penal, al identificar en el anarquismo el agente externo que viene a perturbar el orden de la nación, justifica el carácter de urgencia de la ley, necesaria para "evitar las conmociones que inevitablemente determina, en el cuerpo social, la presencia de ese microbio patogénico" (Cané 58).

I2 Aunque Payró no integra la nómina de los autores argentinos anarquistas, simpatiza con algunos de sus representantes y con algunos de los presupuestos del ideario libertario, tal y como testimonian sus colaboraciones en la revista Martin Fierro, dirigida por Alberto Ghiraldo. El autor de Marco Severi comparte con los colectivos ácratas preocupaciones sociales como la Ley de Residencia o la Ley de Defensa Social y cuestiona, a partir de casos célebres como el del dinamitero catalán Rull, la legitimidad de la pena de muerte. 
I3 Payró recurre al periodismo, al igual que al arte del relato o del drama, como herramienta diplomática y como tribuna desde donde articular sus ideas para el progreso nacional. Como reportero de La Nación, viaja dentro y fuera del país - a Paraguay, Chile, Tierra del Fuego, las provincias de Buenos Aires y las del Norte Argentino - dispuesto a dar cuenta de las peculiaridades geográficas y los conflictos sociales que allí tienen asiento. Como resultado de tales desplazamientos, quedan algunas memorables crónicas tituladas "La pampa de agua", en que se informa de las inundaciones sufridas en la comarca bonaerense, y aquellas que más tarde recopilaría en los libros de La Australia argentina (1898) y En las tierras del Inti. Además de testigo de episodios nacionales, Payró ejerce de interlocutor con sus países vecinos en Cartas chilenas (1895) - con las que intenta mediar entre ambos frentes ante el conflicto en la frontera - y como cronista de guerra en los artículos que se conocen bajo las rúbricas Diario de un testigo (I9I4) y Episodios de la ocupación alemana (1915).

I4 La obra se publica originalmente en forma de crónicas en La Nación entre el I5 de mayo y el 26 de septiembre de 1898 .

I5 De las falanges de soldados, una mención especial merece, por sus victorias en suelo argentino, la Legión Italiana Garibaldina. Su nombre será heredado por los aproximadamente cien mil soldados de Mussolini que viajan en los años treinta al frente de batalla de la Guerra Civil Española como parte de la XII Brigada Internacional.

I6 Según los datos ofrecidos por Payró a propósito del papel que las italianas representaban como madres: "en la clasificación de los nacimientos, las argentinas ocupaban un lugar muy inferior pues sobre 15.939 niños, 7032 tenían padre y madre italianos. Otras cifras en prueba de lo anterior: en la clasificación de los partos, leíanse 7507 italianas y 3984 argentinas" (Los italianos 4I).

I7 Esa es la tesis que asoma en sus artículos recogidos en La Australia argentina: recuperar para la nación las tierras del sur y permitir que en ellas surja el crisol de razas. Al respecto, escribe: “Considero que allí se prepara una raza poderosa: que las fuerzas de la Naturaleza trabajan activamente, en colaboración con las fuerzas sociales que están en perpetuo movimiento y encuentran allí terreno nuevo y libre donde actuar y acrecer" (Payró, Obras 346).

I8 Susana Villavicencio aporta la idea de que las formas y los límites de la ciudadanía argentina son trazados, en los diferentes momentos, por una élite intelectual "que legitima su intervención política en la claridad y racionalidad de sus propuestas" (I4). Conviene retomar aquí la distinción de los dos momentos clave en la construcción de la ciudadanía argentina: uno inicial, basado en la incorporación directa de extranjeros, y un segundo que, a raíz de 
la crisis de tal modelo, trae una nueva mirada sobre la dicotomía "gringo" / criollo. Se pasa entonces del proyecto inmigratorio a un modelo de absorción, que supone la implantación de varios dispositivos asimilacionistas y el fin del pluralismo cultural.

I9 Son tres las obras que encarnan una versión sistematizada de los balbuceos nacionalistas: La restauración nacionalista de Ricardo Rojas (1909); El diario de Gabriel Quiroga de Manuel Gálvez (1910); y El payador de Leopoldo Lugones (19i6).

20 La palabra "tano" es una apócope del "napolitano" y se sigue empleando hoy en día en Buenos Aires para designar a cualquier italiano. El equivalente de este término coloquial fuera de la provincia de Buenos Aires es el de "gringo", mote con el que se designa al extranjero, en particular al italiano.

2I Nouzeilles concluye en su estudio: "el naturalismo fue una máquina policial que colaboró abiertamente con los mecanismos directos de segregación que fueron implementándose en las últimas décadas del XIX" (I8I). Otras aportaciones imprescindibles sobre la elaboración ficcional de la problemática inmigratoria son las de Evelyn Fishburn (198I) y la de Alejandra Laera (2006).

22 Solamente en la primera semana, tras la sanción de la ley en 1902, el número de las deportaciones asciende a quinientas (Oved 275). Dicha medida no será derogada hasta 1958 .

23 Según argumenta Cané en la iniciativa que presenta al Congreso a pedido de la Unión Industrial en I899: "Pero si, como pasa en estos momentos, nuestra tierra sirve de refugio a los anarquistas que vienen a rehacer, con el trabajo fácil que ella les ofrece, las cajas exhaustas de sus asociaciones criminales, la ley de expulsión servirá para evitar que sea con dineros ganados en suelo argentino, que se adquieran las bombas destinadas a matar ancianos, mujeres y niños indefensos, como en el Liceo de Barcelona o los puñales que han de partir corazones tan nobles como el de la emperatriz Isabel o el presidente Carnot" (I24). Con la exclamación del juez, "Hay que enmendar esa ley”, y con un escenario esperanzado por el indulto de Marco Severi se cierra la pieza de Payró.

24 El estigma del extranjero criminal que recae sobre el protagonista de esta obra de Payró ha de leerse en relación con las teorías que, amparadas por las categorías científicas de la antropología criminal, convierten a estos sujetos en "monstruos sociales" (Gacitúa I9), responsables de desestabilizar la vida ordinaria de la joven república.

25 Alicia Aisemberg y María de los Ángeles Sanz distinguen dos variantes en la representación del inmigrante italiano en el teatro de tesis social: por un lado, el arquetipo del trabajador rural - aquel que aparece en La flor del trigo (1908), de José de Maturana, y en Madre tierra (1920), de Alejandro Berruti -, y por otro el arquetipo del dirigente obrero - es el caso de Lorenzo, protagonista de 
La fragua (I912), de Armando Discépolo. A propósito de ambas obras, las investigadoras señalan la complejidad que subyace a la construcción del personaje del inmigrante así como la minuciosa atención que se le dedica. El problema del inmigrante, apuntan, es presentado "de un modo verdaderamente eficaz, desplegando las diversas imágenes que se habían elaborado socialmente alrededor de su figura, mostrándolo desde diferentes ángulos" (Aisemberg y Sanz 63).

La empresa intelectual desarrollada por Ricardo Rojas en La restauración nacionalista gira en torno a una tesis central: la educación del ciudadano, en concreto, su formación histórica, debe tener como principal objetivo el afianzamiento de su conciencia nacional. En las instituciones educativas es donde el hijo del inmigrante se nacionaliza, abandonando su lengua y desarraigándose de la patria de origen. "Imprimir a nuestra educación un carácter nacionalista por medio de la Historia y las Humanidades" (Rojas 222) significa garantizar la integración de los recién llegados, evitar la propagación de otros nacionalismos en el seno de la república, disciplinar y homogeneizar a la masa heterogénea esparcida por la nación y restaurar los rasgos genuinos del territorio y del carácter argentinos. Por su parte, Manuel Gálvez en El diario de Gabriel Quiroga condensa el clima de la época y realiza un diagnóstico de los males de la patria a partir de una oposición de orden temporal entre "pasado heroico y presente caído" (37). De sus páginas, que apelan también a una reconquista espiritual del país, procede el lema "Gobernar es argentinizar", que invierte y se impone sobre el archiconocido "Gobernar es poblar" alberdiano. En contraposición con el argentino viejo de las comarcas montañosas, Gálvez denigra al inmigrante "superficial”, al buscador de fortunas, cuyos actos, vida y sentimientos "convergen en un solo fin: el dinero" (I43). Frente a esas "gentes hambrientas, desmoralizadas" (Gálvez I7I), movidas por un único afán lucrativo, la voz narradora apela a una regeneración colectiva. Otro episodio central de la reacción nacionalista que inaugura el nuevo siglo es el protagonizado por Leopoldo Lugones. En este marco de forja de mitos de fundación, se inscribe su relectura del Martín Fierro, convertido en poema épico y en origen de la literatura nacional, en las conferencias dictadas en I9I3 en el Teatro Odeón y editadas tres años más tarde bajo el título de El payador (r916). Es en esa ocasión donde la inversión del binomio sarmientino civilización y barbarie completa su giro, afianzando su mensaje nacionalista: el gaucho, el desierto, la aldea empiezan a funcionar como anclaje lírico para una imagen renovada de la patria pues, frente a la "plebe ultramarina", "los mendigos ingratos que armaban escándalo en el zaguán” (Lugones 15), son ellos quienes encarnan sus rasgos esenciales. El gaucho, fatalmente sacrificado por la política de la oligarquía liberal, es el verdadero "héroe y civilizador de la Pampa" (Lugones 36), y a partir de este 
momento merece ocupar, desplazando al inmigrante - sujeto sin permanencia y de transitorio arraigo - el centro del imaginario literario e histórico argentino.

27 En la perspectiva quirúrgica de Francisco de Veyga - autor de otro de los textos paradigmáticos del positivismo argentino en que la doctrina política anarquista queda vinculada con el mundo del crimen, Anarquismo y anarquistas (1897) - la miseria y la desigualdad social constituyen los detonantes de la degeneración moral y política pues, a la caterva habitual de locos, tarados y maleantes, se suma otra forma de degeneración, el radicalismo político de los sujetos libertarios. Anarquismo, prostitución y crimen quedan entonces alineados en un horizonte de barbarie sobre el que urge intervenir con operaciones contundentes de reforma social.

OBRAS CITADAS

AN S O L A B E H E RE, P A B L O. Literatura y anarquismo en Argentina (I879-1919). Rosario: Beatriz Viterbo Editora, 20 II.

AISEMBERG, ALICIA Y MARÍA DE LOS ÁNGELES SANZ. "La antinomia inmigrante/criollo en el teatro de tesis social." Inmigración italiana y teatro argentino. Ed. Osvaldo Pellettieri. Buenos Aires: Galerna; Instituto Italiano de Cultura de Buenos Aires, 1999.

altamiran 0, Carlos y Beat RiZ Sarlo. Ensayos argentinos. De Sarmiento a la

Vanguardia. Argentina: Ariel, 1997.

ARGERICH, AN T ONIO. ¿Inocente o culpable? Buenos Aires: Editor J.C. Rovira, 1933.

Bertoni, Li lia anA. Patriotas, cosmopolitas y nacionalistas. La construcción de la nacionalidad argentina a fines del siglo xix. Buenos Aires: Fondo de Cultura Económica, 2007.

CAM B ACERES, Eugenio. En la sangre. Madrid: Editora Nacional, i984. CANÉ, M I U U L. Expulsión de extranjeros. Apuntes. Buenos Aires: Sarrailh, I899. C L EM E Ti, heBE. El miedo a la inmigración. Buenos Aires: Editorial Leviatán, i984. DE VEYGA, FRAn Cisco. Degeneración y degenerados. Miseria, vicio y delito. Buenos Aires: El Ateneo, 1938.

DEv о T o, F E R N n D o. Historia de los italianos en Argentina. Buenos Aires: Biblos, 2006.

Fish B U R , EV L y n. The Portrayal of Immigration in Nineteenth-Century Argentine Fiction (I845-1902). Berlín: Colloquium-Verlag, I98I.

GACIT Ú A, M OYANO, COR NE LIO. La delincuencia argentina ante algunas cifras y teorías. Córdoba: F. Domenici, 1905.

GÁL VEZ, M A N e L. El diario de Gabriel Quiroga. Opiniones sobre la vida argentina.

Buenos Aires: Taurus, 2002. 
GARCía B ARRIENT OS, José LuIS. Cómo se comenta una obra de teatro: ensayo de método. México: Toma, Ediciones y Producciones Escénicas y

Cinematográficas, Paso de Gato, 2012.

García, germán. Roberto J. Payró. Testimonio de una vida y realidad de una literatura. Buenos Aires: Editorial Nova, I96I.

gi us t i, R о B R t o. Estudio preliminar. Teatro Completo. Por Roberto Payró. 7-28. GonZÁle Z LANuZA, EduARD o. Genio y figura de Roberto Payró. Buenos Aires: Editorial Universitaria, I965.

LAERA, A LE JA NDRA. "Contaminaciones: inmigrantes y extranjeros en las representaciones ficcionales de la nación argentina." The Colorado Review of Hispanic Studies 4 (2006): 327-46.

LARRA, RA Ú L. Payró. El hombre. La obra. Buenos Aires: Claridad, 1938.

L U d m R, Jos F In A. Las culturas de fin de siglo en América Latina. Rosario: Beatriz Viterbo, I994.

LuG ONES, LE O O LD o. El payador. Antología de poesía y prosa. Venezuela: Biblioteca Ayacucho, 1979.

mitre, B AR to lo mé. Prólogo. Payró, La Australia Argentina. V- VII.

M ONTES, GRACi E LA. "El proyecto realista en Roberto J. Payró." Historia de la literatura argentina. Tomo III. Buenos Aires: Centro Editor de América Latina, I981. 73-95.

N OUZEILLES, GABR IE LA. Ficciones somáticas: naturalismo, nacionalismo y políticas médicas del cuerpo (Argentina I880-I9Io). Rosario: Beatriz Viterbo, 2000.

oved, IAAcov. El anarquismo y el movimiento obrero en Argentina. México: Siglo XXI Editores, 1978.

Pasto rme rlo, Se rgio. Payró en Pago Chico (I887-I892). Periodismo, revolución, literatura. La Plata: Editorial de la Universidad de la Plata, 2009.

PA Y Ŕ, R B E R TO J. La Australia argentina: excursión periodística a las costas patagónicas. Prólogo de Bartolomé Mitre. Buenos Aires: Imprenta de la Nación, I898.

—. El casamiento de Laucha. Chamijo. El falso inca. Buenos Aires: Editorial Losada, 1985.

—. Divertidas aventuras del nieto de Juan Moreira. La Habana: Editorial de Arte y Literatura, 1976.

-. Evocaciones de un porteño viejo. Buenos Aires: Quetzal 1952.

—. Los italianos en Argentina. Buenos Aires: Imprenta de la Nación, I895.

-. Marco Severi. Buenos Aires: Casa Editora M. Rodríguez Giles, I907.

—. Obras. Selección, prólogo, notas y cronología de Beatriz Sarlo. Caracas: Ayacucho, 1984 .

—. Pago Chico y nuevos cuentos de Pago Chico. Buenos Aires: Capital Intelectual, 2009. 
-. Teatro completo. Estudio preliminar de Roberto Giusti. Buenos Aires: Hachette, I956.

—. Violines y toneles. Buenos Aires: Rodríguez Giles, 1908.

RAMA, Á G EL. La ciudad letrada. Hanover: Ediciones del Norte, I984.

ROJAS, RICARD o. La restauración nacionalista. La Plata: UNIPE, 2010.

SARlo, Beatriz. Prólogo. Obras. Por Roberto Payró. i-xliv.

SCARZANELla, EUGENiA. Ni gringos ni indios: inmigración, criminalidad y racismo

en la Argentina, I890-1940. Bernal: Universidad Nacional de Quilmes, 2003.

T E RÁn, ós CAR. Vida intelectual en el Buenos Aires fin-de-siglo (I880-1910). Derivas de

"la cultura científica." Buenos Aires: Fondo de Cultura Económica, 2000.

Vil la vi E n Ci o, s usana. Los contornos de la ciudadanía. Nacionales y extranjeros

en la Argentina del Centenario. Buenos Aires: Eudeba, 2003. 